California State University, Monterey Bay

Digital Commons@ @ CSUMB

2014

\title{
Advancing Biodiversity Research in Developing Countries: The Need for Changing Paradigms
}

Paul H. Barber

Ma Carmen A. Ablan-Lagman

Ambariyanto

Roberto GS Berlinck

Dita Cahyani

See next page for additional authors

Follow this and additional works at: https://digitalcommons.csumb.edu/sns_fac

\section{Recommended Citation}

Barber, P.H., Ablan-Lagman, C.A., Ambariyanto, Berlinck, R.G.S., Cahyani, D., Crandall, E.D., RavagoGotanco, R., Juinio-Meñez, M. A., Mahardika, I.G.N., Shanker, K., Starger, C.J., Toha, A.H.A.,Anggoro, A.W., and D.A. Willette. 2014. Advancing biodiversity research in developing countries: the need for a new paradigm. Bulletin of Marine Science 90(1): 197-210.

This Article is brought to you for free and open access by the School of Natural Sciences at Digital Commons @ CSUMB. It has been accepted for inclusion in School of Natural Sciences Faculty Publications and Presentations by an authorized administrator of Digital Commons @ CSUMB. For more information, please contact digitalcommons@csumb.edu. 


\section{Authors}

Paul H. Barber, Ma Carmen A. Ablan-Lagman, Ambariyanto, Roberto GS Berlinck, Dita Cahyani, Eric D. Crandall, Rachel Ravago-Gotanco, Marie Antonette Juinio-Menez, Ig Ngurah Mahardika, Kartik Shanker, Craig J. Starger, Abdul Hamid A Toha, Aji W. Anggoro, and Demian A. Willette 


\section{Advancing biodiversity research in developing countries: the need for changing paradigms}

\begin{abstract}
Department of Ecology and Evolutionary Biology, University of California, Los Angeles, California 90095.
\end{abstract}

${ }^{2}$ Biology Department, De La Salle University, Manila 1004, Philippines.

${ }^{3}$ Marine Science Department, Faculty of Fisheries and Marine Science, Diponegoro University, Kampus Tembalang, Semarang, Indonesia.

${ }^{4}$ Instituto de Química de São Carlos, Universidade de São Paulo, CP 780, CEP 13560-970, São Carlos, SP, Brazil.

${ }^{5}$ Indonesia Biodiversity Research Center, Denpasar, Bali 80223, Indonesia.

${ }^{6}$ NOAA Southwest Fisheries Science Center, Fisheries Ecology Division \& Institute of Marine Sciences, UC Santa Cruz, Santa Cruz, California 95062.

${ }^{7}$ Marine Science Institute, University of the Philippines, Diliman, Quezon City, 1101, Philippines.

${ }^{8}$ Fakultas Kedokteran Hewan, Universitas Udayana, Denpasar Bali, Indonesia.

${ }^{9}$ Centre for Ecological Sciences, Indian Institute of Science, Bangalore, India \& Dakshin Foundation, Bangalore, India.

${ }^{10}$ Science \& Technology Policy Fellowships, Center of Science, Policy \& Society Programs, American Association for the Advancement of Science, Washington, DC 20005.

${ }^{11}$ Fishery Department, State University of Papua. Manokwari, Papua Barat, 98314, Indonesia.

${ }^{12}$ Biology Department, Brawijaya University, Malang, East Java, 65145, Indonesia.

" Corresponding author email: <paulbarber@ucla.edu>.

Date Submitted: 2 January, 2013. Date Accepted: 25 September, 2013. Available Online: 4 December, 2013.

\author{
Paul H Barber ${ }^{1 *}$ \\ Ma Carmen A Ablan-Lagman ${ }^{2}$ \\ Ambariyanto ${ }^{3}$ \\ Roberto GS Berlinck 4 \\ Dita Cahyani ${ }^{5}$ \\ Eric D Crandall ${ }^{6}$ \\ Rachel Ravago-Gotanco ${ }^{7}$ \\ Marie Antonette Juinio-Meñez ${ }^{7}$ \\ IG Ngurah Mahardika ${ }^{8}$ \\ Kartik Shanker 9 \\ Craig J Starger ${ }^{10}$ \\ Abdul Hamid A Toha ${ }^{11,12}$ \\ Aji W Anggoro ${ }^{5}$ \\ Demian A Willette ${ }^{1}$
}

ABSTRACT.-The world is in the midst of a biodiversity crisis, threatening essential goods and services on which humanity depends. While there is an urgent need globally for biodiversity research, growing obstacles are severely limiting biodiversity research throughout the developing world, particularly in Southeast Asia. Facilities, funding, and expertise are often limited throughout this region, reducing the capacity for local biodiversity research. Although western scientists generally have more expertise and capacity, international research has sometimes been exploitative "parachute science," creating a culture of suspicion and mistrust. These issues, combined with misplaced fears of biopiracy, have resulted in severe roadblocks to biodiversity research in the very countries that need it the most. Here, we present an overview of challenges to biodiversity research and case studies that provide productive models for advancing biodiversity research in developing countries. Key to success is integration of research and education, a model that fosters sustained collaboration by focusing on the process of conducting biodiversity research as well as research results. This model simultaneously expands biodiversity research capacity while building trust across national borders. It is critical that developing countries enact policies that protect their biodiversity capital without shutting down international and local biodiversity research that is essential to achieve the long-term sustainability of biodiversity, promoting food security and economic development. 
The Earth is in the middle of a biodiversity crisis (Ehrlich and Pringle 2008, Butchart et al. 2010, Rands et al. 2010, Stokstad 2010). Across varied environments and taxonomic groups, contemporary extinction rates are 100-1000 times higher than background rates from the fossil record (Pimm et al. 1995, Levin and Levin 2002, Barnosky et al. 2011); $12 \%$ of all bird species, $23 \%$ of mammals, $32 \%$ of amphibians, $25 \%$ of conifers, and $52 \%$ of cycads are presently threatened with extinction (Butchart et al. 2010), a problem augmented by climate change (Thomas et al. 2004).

However, while scientists warn of the 6th mass extinction (Wake and Vredenburg 2008, Barnosky et al. 2011), response to this crisis has been slow. Modern, technological societies are increasingly disengaged from nature (Pergams and Zaradic 2006, Pergams and Zaradic 2008), obfuscating the importance of biodiversity for human civilization. It is common to hear politicians and business leaders argue that society cannot afford the economic costs (e.g., higher prices or lost jobs) of protecting biodiversity (e.g., Easterbrook 1994, Meyer 1997) despite the fact that the global loss of biodiversity is identified as a major threat to human wellbeing (Diaz et al. 2006, Chivian and Bernstein 2008, Cardinale et al. 2012) and studies have shown that conservation policies in developed countries often have no significant negative economic impact (e.g., Meyer 1995, Freudenburg et al. 1998).

Humans are inextricably dependent on biodiversity for goods (food, materials, pharmaceuticals) and services (carbon storage, nutrient cycling, crop pollination) (Chivian and Bernstein 2008, Mace et al. 2010). The economy vs biodiversity arguments have led economists and conservationists to apply economic models to capture the value of biodiversity goods and services (NRC 2005, Alho 2008) and these values can be remarkably large. For example, Gallai et al. (2009) estimated animal pollinators are worth $\$ 201$ billion per year, or nearly $10 \%$ of the annual global value of all agricultural human food production. Similarly, marine biodiversity in the United Kingdom was valued at $\$ 831$ million per year in food production, $\$ 19$ billion per year in recreational activities, and $\$ 13.7$ billion per year in regulation of atmospheric gases (Gallai et al. 2009), highlighting the value of intact ecosystems.

While some question economic valuation as a biodiversity conservation tool (Shackleton 2001), biodiversity loss has real economic consequences. For example, the collapse and subsequent moratorium of Labrador/Newfoundland groundfish fisheries resulted in the loss of 40,000 fisheries jobs plus additional job losses in related economic sectors (Dolan et al. 2005). Thus, although there are ethical arguments for biodiversity conservation, the loss of ecosystem goods and services associated with biodiversity loss is becoming a major social and economic concern (Hooper et al. 2005).

Biodiversity is disproportionately distributed in tropical developing countries (Myers et al. 2000) and these regions have some of the highest valued ecosystems on a per unit area basis (Turner et al. 2012). Therefore, as biodiversity is lost, the countries that can afford it the least stand to lose the most (McMichael et al. 2008). Southeast Asia is a region of particular concern for biodiversity loss. This region is home to the most diverse marine environments in the world (Roberts et al. 2002, Bellwood and Meyer 2009) and has many terrestrial biodiversity hotpots as well (Myers et al. 2000). Models indicate that Southeast Asia has some of the highest potential and realized ecosystem service values, and highest essential ecosystem services to poor communities in the world (Turner et al. 2012). The pronounced declines and threats to marine (Burke et al. 2011) and terrestrial (Sodhi et al. 2004, Normile 2010) communities 
in this region thus not only represents a biodiversity crisis for Southeast Asia, but also a potential economic crisis in a region seeking economic development.

\section{The Convention on Biological Diversity and its Consequences}

The Convention on Biological Diversity (CBD) was signed in Rio De Janeiro, Brazil, in 1992 in recognition of the importance of biodiversity to human health and economic development. Major goals of this international treaty included the conservation and sustainable use of biodiversity and the fair and equitable sharing of the benefits that developing and developed countries derive from biodiversity resources. The CBD elevated the visibility of biodiversity and its value to society; however, much of the perceived value of biodiversity focused on "green gold" and the pharmaceutical potential of natural products. An estimated $47 \%$ of pharmaceuticals have been derived from natural products (Newman and Cragg 2007, 2010, Cragg et al. 2012). As such, many believed that biodiscovery could provide a strong financial incentive for biodiversity conservation (Shyamsundar and Lanier 1994), and many developing countries enacted legislation to protect their biodiversity resources for economic development. Unfortunately, these economic benefits are not always realized (Shackleton 2001); local stakeholders often received no benefits from benefit-sharing agreements (Prathapan and Rajan 2011) and pharmaceutical companies complained that bureaucratic obstacles prevent successful commercialization of products (Dalton 2004). For example, the Merck-INBio partnership that was designed to fund biodiversity conservation in Costa Rica by granting Merck biodiscovery rights was hailed as a innovative model for advancing economic development, drug discovery, and biodiversity conservation (Blum 1993), but this partnership collapsed in 2013 due to insufficient revenue (Pennisi 2013).

While biodiversity legislation was written "to stimulate the use of biodiversity, not restrict it" (Pennisi 1998), unfortunately in many cases the opposite has occurred. Laws intended to prevent biopiracy (profiting from local biodiversity resources or knowledge without acknowledging or compensating local communities at all) frequently fail to distinguish between activities designed to discover and commercialize biodiversity resources (e.g., biodiscovery) and basic biodiversity and conservation science (Pethiyagoda 2004). Such imprecise and ineffective regulations have resulted in the inability to obtain permits for basic science research and to establish agreements between local and foreign scientists (Rull and Vegas-Vilarrubia 2008), leading to the termination of research collaborations (Ready 2002).

Biopiracy is a legitimate concern in developing countries, particularly those with rich biodiversity resources, because benefit-sharing agreements can be inequitable and/or fail to capture real issues regarding proprietary rights to traditional knowledge (Prathapan and Rajan 2011). On the surface, restrictive legislation regarding biodiversity research may seem to be the best way to protect national interests, but such actions can come at a significant cost. First, one of the primary goals of the $\mathrm{CBD}$ is the conservation of biodiversity, and it is essential to understand the nature of biodiversity to effectively protect it (CBD Articles 6, 7, 8, and 12; Reaka 1997). In the absence of fundamental biodiversity research, we cannot understand the biological composition or ecological function of local ecosystems, limiting our abilities to conserve them. Second, to understand how ecosystems are being impacted by anthropogenic stressors and climate change, and to develop conservation measures, 
it is essential to have longitudinal data that allows the comparison of an ecosystem in the past and present to determine what is natural (CBD Articles 7 and 14; Willis and Birks 2006). Without this basic biodiversity research, we lack the essential baseline data regarding ecosystem health, making us blind both to its degradation and potential recovery. Third, and perhaps most significant, achieving and documenting the sustainability goals of the CBD requires biodiversity scientists who are knowledgeable in local flora and fauna (CBD Articles 12 and 13). As biodiversity research is curtailed in the name of preventing biopiracy, so too are training opportunities for students living in biodiversity rich countries. As a result, biodiversity expertise is failing to meet the demand for biodiversity research, particularly in the most biodiverse regions of the world (Sodhi et al. 2004, Rodrigues et al. 2010).

To achieve the conservation and sustainability goals of the CBD, it is essential that developing nations across the world benefit from their biodiversity resources. Here, we explore the challenges of biodiversity research in developing countries and propose models for advancing research in these biodiversity hotspots. We focus largely on Southeast Asia, a region that has the potential (and need) to realize significant benefits from the tremendous concentration of marine and terrestrial biodiversity in the region (Turner et al. 2012). Southeast Asia is facing a major biodiversity crisis. This region has the highest rate of deforestation in the world and is poised to lose $42 \%$ of its terrestrial biodiversity (Sodhi et al. 2004) and marine ecosystems are severely threatened as well (Burke et al. 2011); however, there is minimal research effort focused in this region (Sodhi and Liow 2000, Fisher et al. 2011). While many factors contribute to the paucity of biodiversity research (see below), protecting the biodiversity of this region and the benefits derived from it will require lowering obstacles to biodiversity research, advancing both basic and applied conservation science in Southeast Asia.

\section{Challenges to Biodiversity Research in Southeast Asia}

Challenges to biodiversity research are nearly universal. Even in developed countries like the US, it can take months or years to obtain permits to collect animals for research that could be collected for recreational use with a hunting or fishing license. However, a combination of limited infrastructure, weak institutions, and poor funding can make conservation in tropical counties especially challenging (Barrett et al. 2001), a pattern that holds true for Southeast Asia.

AcCess to Resources and Facilities.-Field stations and marine laboratories provide essential logistic and support services to biodiversity scientists and students, providing classrooms and wet/dry laboratory space, animal holding facilities, boats and field transportation, and easy access to biologically diverse environments in support of research and education activities. World-class facilities draw research teams from all over the world, stimulating local research effort and opportunities for collaboration with local scientists. Conversely, a lack of this infrastructure can severely hinder both local and foreign-supported research, even in areas with extraordinary biodiversity

Currently, there are more than 45 marine field stations in the Caribbean, with half located in developing nations (Table 1). Multi-national marine institute organizations such as the Association of Marine Laboratories of the Caribbean further 


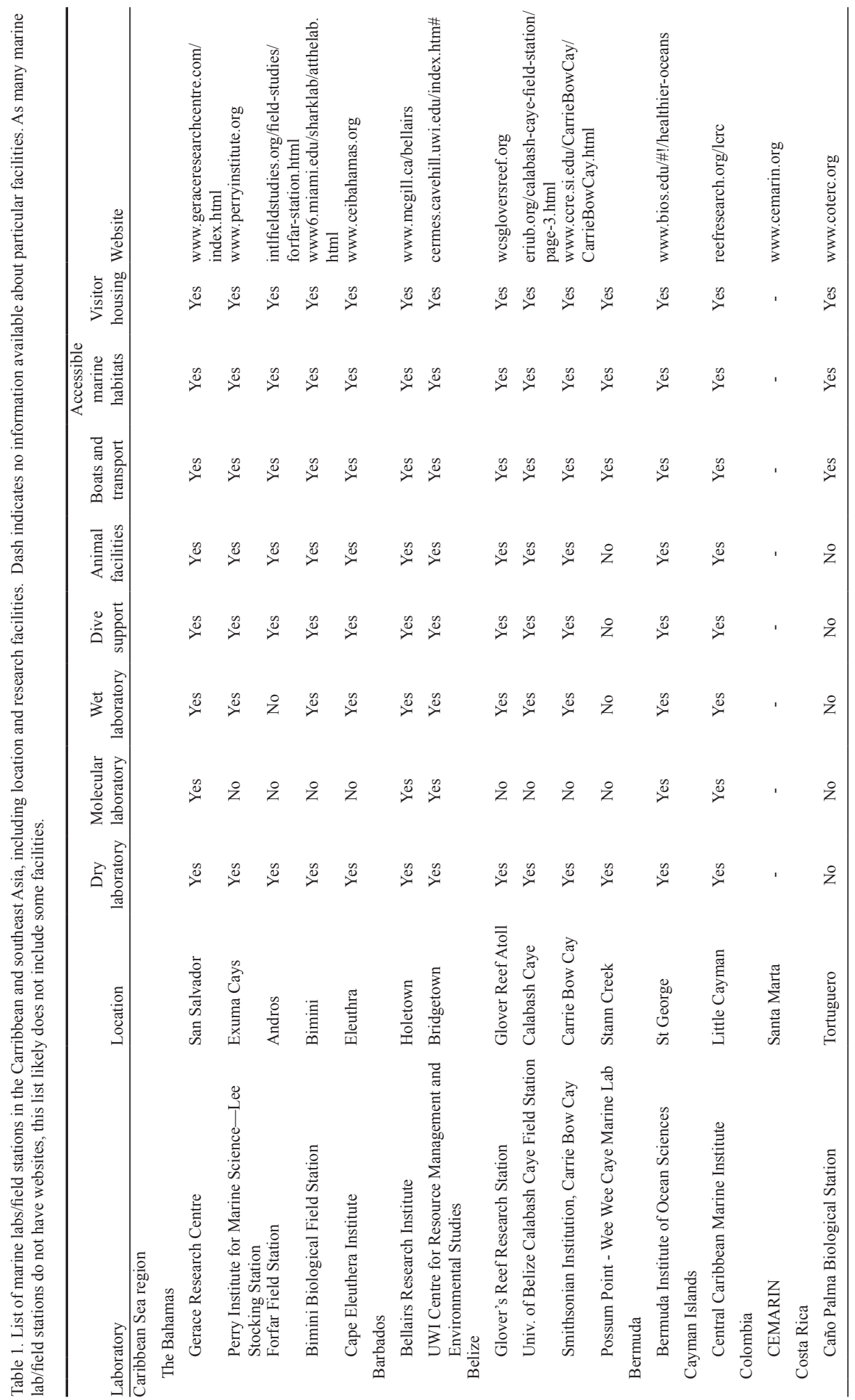




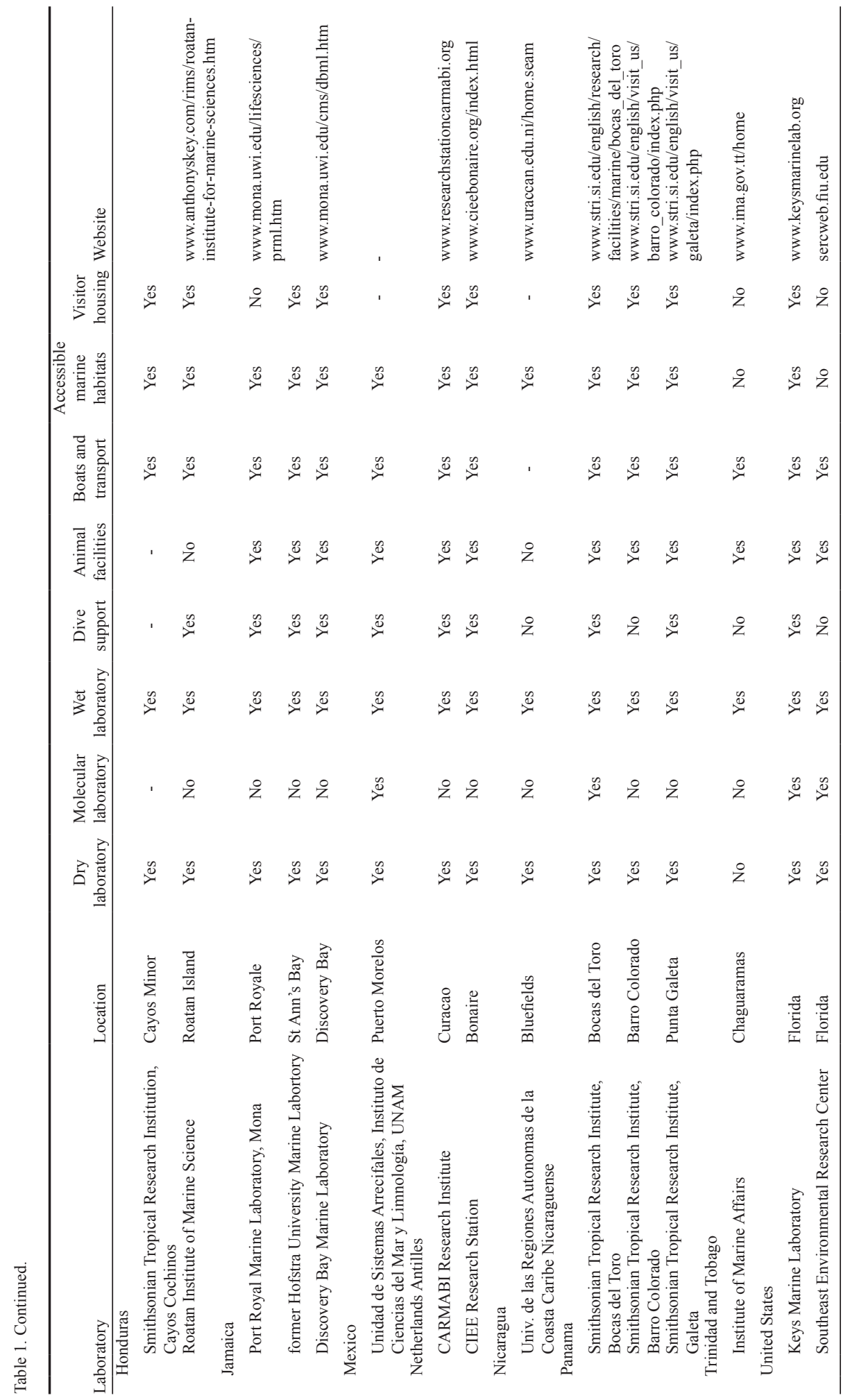




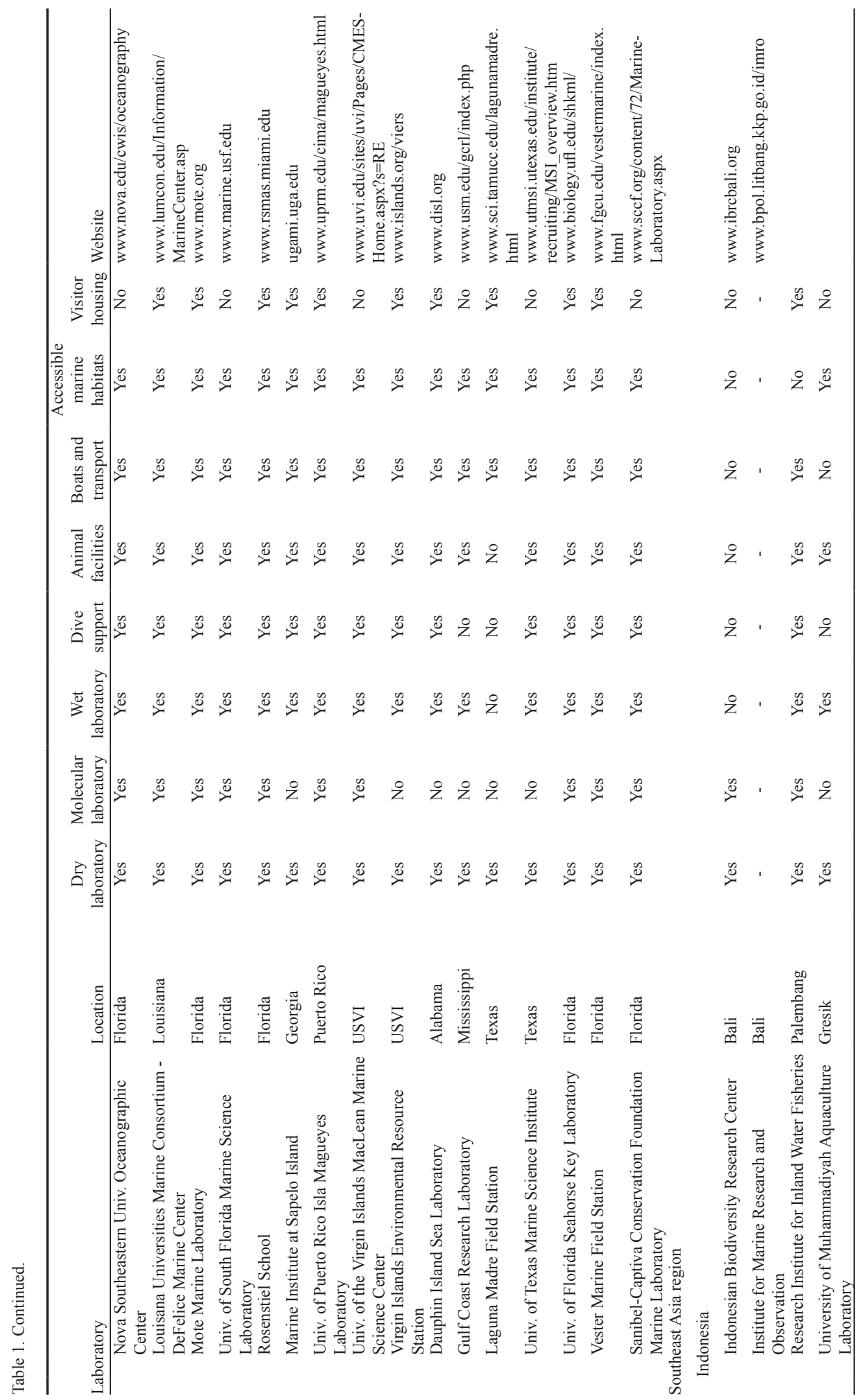




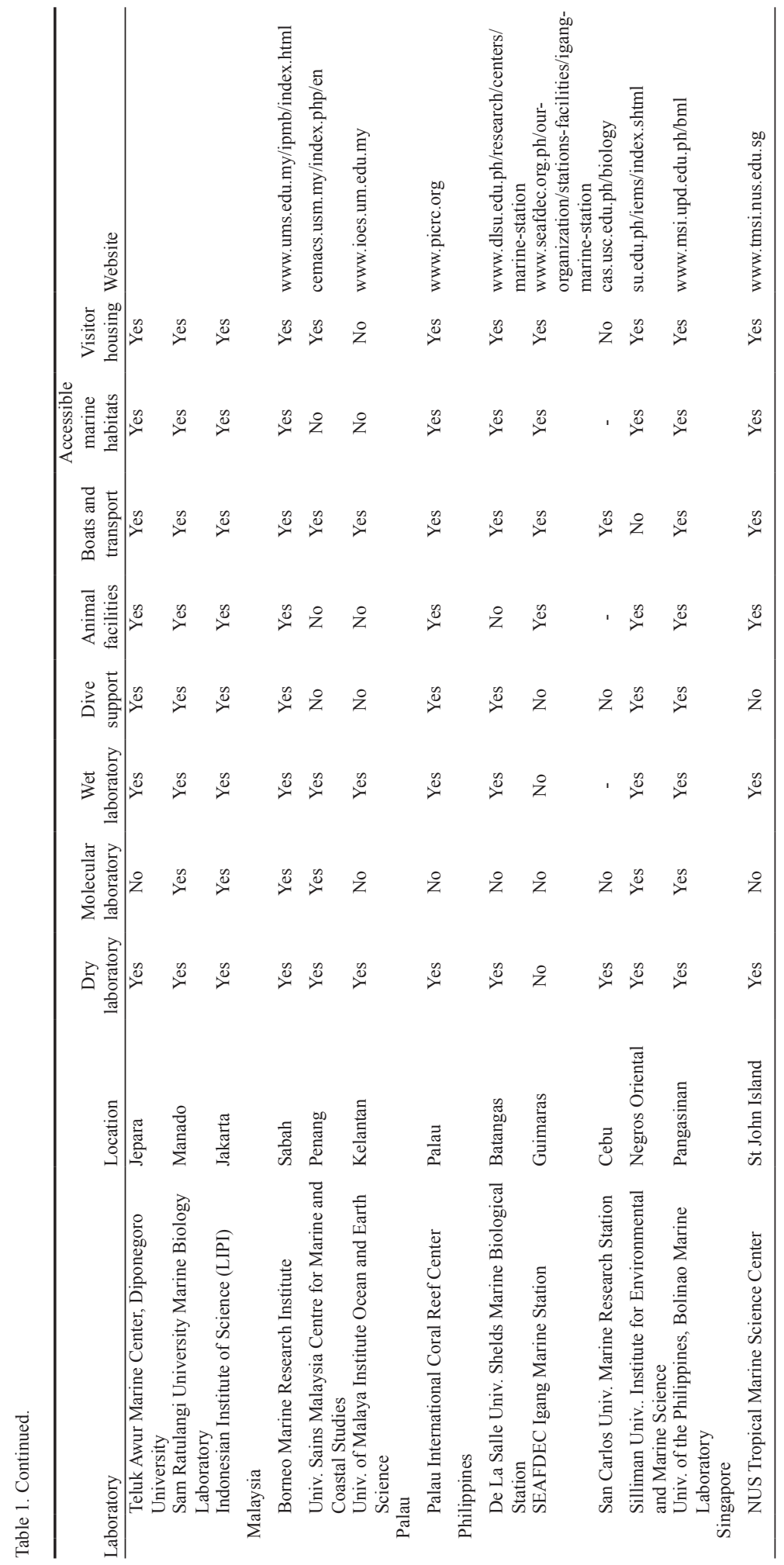


advance marine science research through the exchange of research and technologies between laboratories, helping marine scientists overcome cultural and social barriers, and promoting sustainability of small laboratories with modest budgets. In contrast, field stations and marine laboratories are more limited in Southeast Asia (Table 1) and there are no similar multi-national consortia among marine laboratories and field stations in Southeast Asia, reducing their overall impact. Furthermore, the distribution of facilities in Southeast Asia is highly variable in both quantity and quality. For example, in the Philippines, there are a number of laboratories throughout the country with basic laboratory equipment for alpha taxonomy work and a growing number have access to laboratories that can carry out molecular genetic analyses. In contrast, in countries like East Timor and Papua New Guinea, laboratory and field stations can be quite limited or non-existent. Although these shortcomings partially can be compensated through the ad-hoc initiatives of individual scientists or institutions, but such efforts are often temporary and are not widely known through the international research community, lessening their impacts.

While all biodiversity laboratory/field facilities are valuable resources, facilities in Southeast Asia generally lack the level of infrastructure and administrative support that many western scientists have come to expect from facilities such as the Smithsonian Tropical Research Institute, La Selva Biological Station, or Lizard Island Research Station. In the absence of world-class facilities to attract and support biodiversity researchers from around the world, research effort tends to focus on a limited number of regions with well-developed research infrastructure (Fisher et al. 2011). The need for marine facilities is particularly acute because many governments, including those in south Asia, often focus their limited funding and human resources on terrestrial ecosystems, with little attention to marine biodiversity and conservation.

Increasing biodiversity research capacity in Southeast Asia will require building and operating field stations and marine laboratory to international standards. Developing these research facilities represents a significant investment. However, just as investments in transportation infrastructure promote local economic development by facilitating the movement of goods locally and internationally, the investment in research infrastructure returns tangible dividends. High quality research facilities support local scientists, promoting research that will advance development of the science and technology sectors of the economy. These facilities also attract foreign collaborators that bring with them much needed expertise and funding. The result is a significant increase in number and impact of publications produced by the local scientific community (Leta and Chaimovich 2002), which raises the visibility of the science and the scientific challenges faced by developing countries. While scientific publications may appear to have limited value for developing economies, basic research is the foundation of applied research that leads to economic development (Mansfield 1995, May 1997).

FUNDING.-Despite humanity's dependence on biodiversity for goods and services (Mace et al. 2010), funding for biodiversity research is limited. Biodiversity research areas like taxonomy, systematics, phylogenetics, and ecology are not identified as priority research areas of most national funding agencies. For example, the entire budget for the U.S. National Science Foundation Directorate for Biological Sciences was $\$ 712$ million in 2011, of which only $\$ 272$ million was allocated to Environmental 
Biology or Biological Infrastructure, the two divisions most closely focused on biodiversity research. In comparison, over $\$ 32$ billion was appropriated to the National Institutes of Health in the same year.

Although many Southeast Asian countries recognize the value of biodiversity, national funding for research (e.g., including infrastructure, training, and research activities) is limited. In 2010, G-8 governments invested approximately the equivalent of $2 \%$ of national GDP in research and development. In contrast, during the same period, the Philippines and Indonesia invested $0.1 \%$ or less into research (World Bank 2013a), resulting in measurable research deficits. For example, the Government of Indonesia only produced 437 new research patents during 2008 (1.8 per million residents). This number is much lower than the 818 new research patents in Malaysia (33 per million residents) and 902 in Thailand (13.9 per million residents) (World Bank 2013b), each of which spent nearly 2.5-10 times more of their GDP on research funding (UNESCO 2013), showing a clear link between research investment and potential for economic growth.

Compounding the challenges of limited funding is that funding models in many Southeast Asian countries focus on short duration projects (1-2 yrs) and applied research. For example, funding for marine research in the Philippines and Indonesia frequently prioritizes increasing production of commercially important species, and/ or other technological applications linked to livelihood or industry development. While applied research is an economic necessity in countries with limited research funding, it is important to note that basic biodiversity research can play an important role in conservation and sustainable development (Mikkelsen and Cracroft 2001, Drew et al. 2012) and can feed directly into applied studies. For example, genetic biodiversity assayed through molecular and genomic tools is recognized as essential for improving aquaculture production and in understanding population connectivity for fishery management and conservation (e.g., MPA networks; see Beger et al. 2014, von der Heyden et al. 2014), leading to improved food security. Therefore, basic and applied biodiversity research should not be viewed as mutually exclusive.

EXPERTISE.-A major challenge in advancing biodiversity studies in developing countries is the limited number of local researchers. For example, UNESCO (2013) shows that Indonesia has the equivalent of 21,275 full-time researchers (89.5 per million residents) in all scientific fields compared to 1.41 million in the US (4650 per million residents). As other research is prioritized over biodiversity studies, there is a dearth of expertise in alpha taxonomy and systematics with taxonomic expertise in Southeast Asia, and this is frequently limited to a small number of taxa, limiting local capacity for biodiversity research.

Developing intellectual capacity for biodiversity research in Southeast Asia will require facilities and funding to support biodiversity research (above) as well as engagement of the international scientific community as the bulk of taxonomic expertise exists in developed nations. The practice of "parachute science" (western scientists briefly conducting field research in a developing country then completing the research in their home country) constrains the realization of greater benefits for all parties in collaborative research. The result is a lack of trust of "foreign researchers" who are frequently viewed as exploitative by Southeast Asian governments and researchers. 
Biodiversity research in Southeast Asia would benefit greatly if scientists from developed nations engaged more fully with local research communities. Establishing a set of accepted good practices that includes real collaboration and training opportunities for local scientists would help differentiate basic biodiversity research from exploitive enterprises. Digitizing museum records, publishing results in open-access journals, and developing free online courses would also facilitate building biodiversity expertise in developing countries.

It is also essential that western scientists understand the value of local scientific and traditional ecological knowledge (Drew 2005), which can be can be expansive and insightful. Ignoring this valuable resource wastes valuable knowledge accumulated over centuries and fosters the false belief that western scientists' knowledge is superior to that of local scientists and communities. Furthermore the success of long-term biodiversity monitoring programs may depend greatly on the level of integration of local communities, adaptation to local context and adequate support (Danielson et al. 2003). Therefore, advancing biodiversity research and conservation in Southeast Asia will require greater collaboration and integration of local communities in conservation planning, decision making, and the generation of knowledge (Danielson et al. 2003).

Cultural.-Western researchers are often unfamiliar with languages, cultures, and scientific norms of Southeast Asia. As such, they most often bypass some of our planet's most diverse and unexplored ecosystems. For example, most coral reef research effort focuses on the Caribbean and the Great Barrier Reef (Fisher et al. 2011) because of the easy access to English-speaking field stations-largely ignored is the Coral Triangle, which is the most biodiverse marine ecosystem in the world. This phenomenon is a loss to (1) scientists from developed countries who miss out on the opportunity for discovery, (2) scientists in developing countries who could benefit from collaborations with foreign experts, and (3) biodiversity conservation, as researchers fail to provide data necessary for sustainability efforts.

Conservation programs have been known to fail because of the cultural, social, and economic differences between local communities and developed countries that fund them (Keppel et al. 2012). Therefore, successful international collaboration in Southeast Asia requires that local and western scientists appreciate the differences in cultural norms. For example, behavior perceived as normal to a western scientist (e.g., standing with one's hands on one's hips, leaning on a counter, wearing tight or revealing clothing) may be offensive in Southeast Asia, undermining personal relationships and creating obstacles to collaboration. Many western universities have cultural centers or offices of international programs that prepare students for overseas educational activities. Scientists would benefit greatly by tapping into these resources to reduce cultural misunderstandings.

It is equally important to understand the differences among scientific cultures. Desirable outcomes and the means used to obtain them vary greatly across cultures and these differences can create misunderstandings, potentially leading to misconduct in scientific research (Davis 2003). The real or perceived pressures from funding sources, superiors, and the "publish or perish" notion in academia (Clapham 2005, De Rond and Miller 2005) can lead to behaviors that are viewed as acceptable in one culture, but not another (Ahmed et al 2003). Such variation highlights the need for bridging cultural differences to ensure that the quality and legitimacy of research 
is never compromised. Immersing visiting scientists in the culture and scientific community of the host country or vice-versa can help build trust and cross-cultural understanding among all parties, providing a strong foundation for sustained collaboration (below).

While cultural differences are impacting biodiversity research in Southeast Asia, so too can cultural agreement. Many developing countries require foreign researchers to have a local collaborator as a precondition of a research permit. However, inequality in training and access to resources combined with strong incentives for local researchers to publish in international journals frequently leads to honorary authorship. Western scientists often accept honorary authors as an expeditious path to permits and completing their research, while local scientists are frequently willing to be honorary authors to advance their careers. A recent study suggests that $25 \%$ of research papers have honorary authors (Wislar et al. 2011). While ethical concerns call for an end this practice (Greenland and Fontanarosa 2012), there are larger concerns in developing countries. First, honorary authorship denies local scientists the ability to develop their research abilities. Second, it creates the perception that the local scientific community may be stronger than it is. Advancing biodiversity research in developing countries requires ending the culture of honorary authorships. Scientists from developing countries should insist their contributions extend beyond obtaining permits and samples and scientists from developed countries must engage their local counterparts as true collaborators. Including such "best practices" as part of Memoranda of Understanding, and clearly articulating author contributions on scientific publications would substantially reduce the practice of honorary authorship.

PermitTing.-Obtaining permits for biodiversity research is always a challenge, whether in developed or developing countries. However, obtaining permits while speaking a foreign language, working in an unfamiliar culture, and negotiating a new bureaucracy is a unique challenge. Even for local researchers, the process of obtaining permits in developing countries can be laborious, limiting biodiversity research in regions that need it the most.

Frequently, permitting requires dealing with multiple agencies, and coordination between those agencies can be limited. Working on endangered species, in marine protected areas, and/or exporting samples can be particularly challenging. In some cases, permitting laws are so strict as to make biodiversity research almost impossible. For example, in India, the Biodiversity Act of 2002 strictly prohibits the export of specimens, creating significant obstacles for the advancement of taxonomic studies in the country (Madhusudan et al. 2006, Rajan and Prathapan 2009, Prathapan and Rajan 2009, Bhaskaran and Rajan 2010). Complicating matters is that permits often must be processed in person, creating a burdensome time expense for local researchers and permitting uncertainty for foreigners. Given the limited funding and expertise in many developing biodiverse nations (above), streamlining permitting procedures would help attract more foreign researchers, providing increased opportunity for collaboration and development of the scientific communities in developing biodiverse countries. 


\section{Toward Better Models for Advancing Biodiversity Science}

Given the substantial challenges above, advancing biodiversity research in developing countries will require employing new paradigms. Specifically, research efforts in developing countries need to (1) help contribute to the development of research infrastructure and educating local students in biodiversity science, (2) be creative to leverage funding for biodiversity research, (3) adopt a new way of training local and foreign students that builds biodiversity research capacity from the inside and outside and fosters cross-cultural understanding, and (4) adopt permitting systems that foster research, rather than prevent it. These goals are lofty and challenge the very way that most science is done by emphasizing the process of conducting the sciences rather than just the results. Below we highlight several examples that serve as valuable case studies for achieving these aims.

Case Study 1: Partnerships in International Research and Education (PIRE).--In 2006, the US National Science Foundation initiated the PIRE program to fund collaborative international research projects that emphasized both research results and educational outcomes. In 2007, the Coral Triangle PIRE Project, a consortium of three US universities plus five universities and two government agencies in the Philippines and Indonesia, was funded to investigate the origins of high levels of biodiversity in the Coral Triangle. This program employed a model where the project augmented existing genetic laboratory facilities in the Philippines and Indonesia, creating satellite laboratories suitable for the international research and education goals of the project. US graduate students and postdoctoral scholars worked in these labs for an entire year, and most of the research was conducted in the context of collaborative research-intensive short courses for US, Filipino, and Indonesian undergraduate students.

Developing satellite laboratories is a recent trend with recognized benefits (Service 2012). In this PIRE project, Filipinos and Indonesians benefited from improved laboratory infrastructure, research funding, and new educational opportunities. The Americans benefited from access to local laboratories, the extensive experience of local partners, and local funding that complemented NSF funds. However, there were also significant challenges. Filipino and Indonesian partners had to ensure proper personal and research conduct of US counterparts, as infractions have greater consequences for hosting scientists than the US visitor. Filipino and Indonesian collaborators also struggled to meet the high research infrastructure expectations of the Americans. American partners were challenged by the differences in educational systems and frustrated by a slower rate of research progress. Moreover, maintaining the collaborations after the end of the project has required commitment and dedication of both parties.

While challenging and time consuming, this model has been a strong success. To date, the CT-PIRE program has published more than 15 collaborative research articles (many of which appear in the present issue: DeBoer et al. 2014a,b, Raynal et al. 2014, Willette et al. 2014a,b). This project has also stimulated at least eight successful research proposals to programs such as the National Evolutionary Synthesis Center, local ministries in Indonesia and the Philippines, USAID, and even another NSFPIRE. All US graduate students involved with the project developed theses focused on the Coral Triangle region, and numerous US undergraduate participants have 
returned to the region, funded by programs like Fulbright. Combined, the activities of the CT-PIRE project are truly expanding research capacity focused in the Coral Triangle, both locally and internationally, highlighting the value of this model.

The CT PIRE project has been even richer in intangibles, such as the development of mutual trust, the patience and flexibility to overcome cultural misunderstandings among international laboratories, and developing managerial and pedagogical experience for more senior US participants. It has also made US students and researchers much more aware of the scope of biodiversity research in Indonesia and the Philippines and their national research priorities. While these intangibles are not quantified as easily as numbers of publications, they may end up being more important in transforming ecology and evolution research in the Indo-Pacific region.

With a budget over $\$ 2.5$ million, it is unreasonable to expect that the PIRE model can be fully replicated frequently. However, even with modest budgets it is possible to embrace the philosophy of this program-extended collaboration between scientists from developed and developing countries. Cost of living is generally very low throughout much of the developing world meaning that on-the-ground costs for foreign researchers to extend their fieldwork are relatively minimal. By budgeting more time to conduct field research, one can spend more time working closely with local scientists and establishing mentoring relationships with local students. Such nascent collaborations can then be strengthened and extended as usual: through co-authoring and submission of papers and grant proposals, committee memberships, sabbaticals, etc., resulting in significant benefits for all parties (e.g., Casiligan et al. 2013).

Case Study 2: Indonesian Biodiversity Research Center.-In 2009, the United States Agency for International Development (USAID) Indonesia mission launched a funding initiative, "Supporting Universities to Partner Across the Pacific" to foster partnerships between US and Indonesian universities in an effort to improve the quality and access to higher education in Indonesia. Although this program did not specifically target biodiversity research, it funded the formation of the Indonesian Biodiversity Research Center (IRBC, http://www.IBRCBali.org) a new institution devoted to advancing biodiversity research in Indonesia.

The goal of the IBRC is to foster biodiversity research by providing US and Indonesian students and scientists' modern biodiversity laboratory facilities (microscopy, digital imaging, molecular genetics) and training courses in modern biodiversity science. Formal educational activities at the IBRC consist of a series of four 2-4 week-long research-intensive courses (Scientific Diving, Molecular Ecology and Evolution, Biodiversity Inventories, Phylogenetic Analysis). These courses are taught by leading western scientists and integrate formal lectures, hands on laboratory training, and intensive fieldwork. Funding from USAID supports the training of up to 24 Indonesians during the summer courses and 6-8 Indonesian students/scientists are funded to conduct year-round research at the IBRC following completion of their training. A total of 8-10 US graduate and undergraduate students also join these courses. From 2009 to 2012 the IBRC has served an average of 50 participants per year and research conducted by IBRC students has been published in international journals. Furthermore, the modest 3-yr investment of $\$ 650,000$ by USAID has attracted more than \$6 million in grants to both US and Indonesian scientists for additional biodiversity research showing the strong success of the IBRC. 
There are several aspects key to the success of the IBRC model. First, it provides access to facilities, supplies, and managerial staff to support research. These resources allow students and scientists at the IBRC to focus on pursuing their research interests, helping them to develop into independent biodiversity researchers. Second, the IBRC is dedicated to fostering strong connections between Indonesian scientists and international collaborators. Having short courses taught by western scientists gives Indonesian students access to world-class training in biodiversity science that is not available locally. By attracting additional biodiversity expertise into an extremely understudied region of Southeast Asia (Fisher et al. 2011) these courses foster collaborations between western and Indonesian scientists, stimulating further research in the region and graduate training opportunities for Indonesian students overseas. Third, resident researchers at the IBRC take English language classes so that they can more easily communicate with potential collaborators and publish results in international journals. Fourth, by investing directly in biodiversity research and training of biodiversity researchers, the IBRC is helping change the culture of research in Indonesia by demonstrating that limited facilities and research funding does not have to impede high quality research output.

While successful, this model is not without its challenges. First, some students simply perceive research training as a job, a way to better their position or rank at their home institution rather than important investment for their nation's future. Second, while activities at the IBRC have succeeded in training students and stimulating a desire to continue with biodiversity research, there are limited positions for this new research capacity in Indonesia and limited opportunities for graduate studies or jobs overseas. Thus, while the IBRC is building capacity, there may not be enough positions to absorb this capacity, precluding meaningful long-term growth of biodiversity research capacity in Indonesia. Third, language differences combined with significant cultural differences between western and Indonesian universities has required that western faculty rethink their pedagogical approach. This process can take multiple years, limiting the initial impact of such a center. However, despite these challenges, the IBRC has been tremendously successful, providing greatly expanded training opportunities and funding for biodiversity research in Indonesia. Therefore, for developing countries with limited funding and expertise, investing in research facilities like the IBRC is a productive model for leveraging limited funding into significant growth in research capacity.

Case Study 3: USAID PEER Program.-Limited funding for research in developing countries constrains access to the training and facilities needed to conduct biodiversity research. US federal science agencies, such as the National Science Foundation (NSF) and National Institutes of Health (NIH), that fund American scientists conducting research in developing countries may simultaneously place limits on spending those funds directly on foreign nationals. For example, initially the NSFPIRE program strictly prohibited the hiring for foreign-born postdoctoral associates or graduate students, although inclusion of non-US participants could be funded on a limited basis through the "participant support" category.

To rectify funding inequities between US and foreign collaborators, USAID has partnered with NSF and NIH to create the Partnerships for Enhanced Engagement in Research (PEER) program to financially support collaborative research aligned with USAID's development objectives. In selected countries with USAID missions, 
local scientists can apply to the PEER program to fund collaborations with NSF and NIH-funded researchers. NSF and NIH funds the US portion of the collaboration and USAID funds the developing country scientists as a form of international development aid. Several Indonesian and Filipino partners of the CT-PIRE project (above) were successful in applying for these PEER awards.

PEER directly benefits scientists in developing countries by providing much needed research funding. However, the value of this model is much greater. First, PEER is introducing or reinforcing the importance that research grants should be awarded competitively through a peer-review process-this is standard in many western countries, but is not a universal model. Second, the program emphasizes developing strong partnerships between local and US scientists and having impacts that extend beyond the principal investigator(s). Thus, this program rewards the investigators who can develop the best ideas, the strongest collaborations, and propose projects that will broadly develop physical or intellectual research capacity, improving the long-term prospects for science in these countries. Another key advantage of this model is that it places developing country scientists directly in the role of lead investigator. While this role is familiar to most western scientists (and from a few developing countries with stronger science communities), it can be a novel role for many scientists from developing countries. Being lead PI helps these scientists build their managerial skills and enter into collaborations with US scientists more as equals. As a result, these collaborations raise the profile of researchers in developing countries and makes it is less likely that there will be issues of honorary authorship. Combined, the outcomes of the USAID PEER program should be improved science infrastructure and a more vibrant, collaborative, internationally engaged science community both in the US and in developing countries. Such a result could be instrumental in helping break down some of the barriers that limit biodiversity research in these regions.

CASE StUdy 4: LeSSONS FROM BRAZIL.-While the above examples highlight productive models for advancing biodiversity research in Southeast Asia, it is important to consider how other biodiverse countries have developed research capacity and approach international collaboration. A particularly instructive example is Brazil, one of the world's most biodiverse countries (Fearnside 1999, Jenkins 2003, Pimenta et al. 2005) that has used its natural and human capital to develop into the world's $6^{\text {th }}$ largest economy.

For much of the $19^{\text {th }}$ and $20^{\text {th }}$ centuries Brazilian biodiversity was harvested extensively, resulting in significant loss of forest area (Dean 1995). For example, the Atlantic forest of Brazil was reduced to $<16 \%$ of its original size (Ribeiro et al. 2009). In 1994, the Brazilian federal government launched the National Program on Biological Diversity (PRONABIO) and the Brazilian Ministry of Environment developed the National Biodiversity Policy in an effort to achieve the goals of the CBD, but without curtailing economic growth. The articulation of clear national priorities with respect to biodiversity resulted in policies promoting the restoration of the Atlantic forest (Rodrigues et al. 2009) and the conservation of Brazilian biodiversity, highlighting the importance of establishing biodiversity as a national priority in megadiverse countries.

A central aspect of Brazilian national policy was an emphasis on growth in scientific capacity, including research programs on biodiversity and biodiscovery. This goal 
was achieved through a commitment to strengthen the access to research resources and facilities, increased funding, and programs to foster partnerships and collaborations with scientists from developed countries (Brito Cruz and Chaimovich 2010). A prime example of this commitment is the "Science without Borders" program, a nationwide science, technology, engineering, and math (STEM) scholarship program with the goal of training 100,000 Brazilian students at leading international universities by 2014. Emphasis on science education and training helped Brazil climb to $13^{\text {th }}$ in global rankings of science publications (Regalado 2010), fostering the growth of the science- and technology-based economy that contributed to economic growth and a decrease in poverty (Ferreira de Souza 2012), outcomes critical to biodiversity conservation (Adams et al. 2004).

Investment at the national level was accompanied by an increased investment in biodiversity research and education at the state and local level. For example, in 1999 the São Paulo state funding agency Fundação de Amparo à Pesquisa do Estado de São Paulo (FAPESP) launched the BIOTA-FAPESP program to promote biodiversity research, catalogue biodiversity and promote sustainable use of biodiversity resources (Joly et al. 2010). BIOTA-FAPESP inspired other Brazilian states to establish similar programs and in 2009, the Brazilian federal government launched the national program for biodiversity research. Thus, initial investments in biodiversity research facilities and education resulted in an increased awareness for the greater need for biodiversity research in Brazil, emphasizing the value of governmental investment in biodiversity research. A critical result of these efforts to promote research and education on biodiversity in Brazil is that the large majority of Brazilians currently consider biodiversity conservation as very important (UNEP 2011).

\section{Moving Forward Toward a New Paradigm}

While there are many challenges to biodiversity research in regions like the Coral Triangle (above), there are also many positive developments in the growth of research across Southeast Asia. For example, the $4^{\text {th }}$ amendment to the Indonesian constitution now requires that $20 \%$ of government spending go toward education, to reduce disparities in access to education, to enhance teaching quality, and to support access to resources and facilities in research. Furthermore, Indonesia has set a goal to invest the equivalent of 3\% of GDP into science research to "build quality and competitive human resources, infrastructures, and institutions for Science and Technology" (http://www.ristek.go.id/). Similar increases in investment are occurring in the Philippines as well, and governments throughout Southeast Asia are creating local or regional partnerships to try to maximize the impact of limited resources.

Biodiversity conservation in developing countries is essential for economic growth (Fuentes 2011), food security (Toledo and Burlingame 2006), and sustainable development (Lovejoy 1994, Tisdell 1999, Langlois et al. 2012), all keys to conservation of biodiversity resources. Brazil has enjoyed tremendous economic growth, yet deforestation has dropped to the lowest levels in 20 yrs (Tollefson 2012), indicating that biodiversity regulations combined with education, economic diversification, and scientific development can simultaneously improve biodiversity sustainability and foster economic growth. For most countries in Southeast Asia, the training of 100,000 students in overseas universities, as in Brazil's "Science without Borders" program, is currently unrealistic. However, significant progress towards can be made 
in other ways. Integrated long-term institutional development programs designed to improve partnerships with countries and institutions that have more scientific expertise and financial resources can help build and strengthen the research capacity needed to study and promote sustainable development of biodiversity resources in developing countries. Creating data repositories that raise the visibility of the efforts of local scientists, would aid in catalyzing those partnerships. Through national policies that encourage and foster international collaboration, biodiverse developing countries could take meaningful initial steps toward strengthening and accelerating the growth of local research capacity, and in turn, economic development. It is important to note that international collaboration need not be limited to Southeast Asian scientists partnering with western scientists. Collaboration among scientists from countries across Southeast Asia is also an important form of international collaboration that makes the most use of existing expertise and research capacity.

Unfortunately, the governments of many developing nations are discouraging the very collaboration with foreign scientists needed to promote biodiversity research and foster the growth of their science communities because of misdirected fears of biopiracy. A key lesson from Brazil is that it is essential to engage the international scientific community. It is also critical to have clear policies that acknowledge the value of biodiversity, sending a critical message regarding the need to protect national biodiversity resources for sustainable economic development. However, restrictive policies that make biodiversity research nearly impossible are counter-productive. Governments in biodiverse developing countries should encourage biodiversity research and invest in facilities that support local scientists and attract leading international scientists. Biodiscovery should be appropriately regulated so that developing countries benefit economically from their biodiversity resources and traditional knowledge, but permitting needs to differentiate between biodiscovery and biodiversity science. Furthermore, permit procedures need to be streamlined so that the limited resources available for biodiversity research can be invested in actual research.

Hybrid research/education models hold tremendous promise for changing the way that biodiversity research is conducted in developing countries, maximizing the collective benefits realized from biodiversity research. However, while the participation of foreign biodiversity experts should be encouraged, it is critical that scientists from developed countries realize that the benefits of this research must extend beyond the data collected. Biodiversity scientists from developed countries have an obligation to build research capacity in the developing countries in which they work.

International research/education partnerships can have strong mutual benefits, but require a shift in thinking. Funding agencies and local governments need to appreciate the importance of collaborative research between developing and developed countries, and encourage research programs that have results that extend beyond the data produced. These partnerships need to be appropriately valued within the scientific community and university administrations so that scientists will invest the time and resources to pursue true collaborations rather than take the shortest path to publication. The models above are examples of the kinds of programs needed to advance biodiversity research in developing countries, but this is not an all-inclusive list. There are many creative ways to achieve meaningful international collaborations that advance biodiversity research while building science capacity in developing countries. The key is to take a broader, more inclusive view of the desired outcomes 
of collaborative research, one that builds a foundation of mutual trust and benefits all partners through advancing biodiversity science.

\section{ACKNOWLEDGMENTS}

The authors thank the National Science Foundation (grants OISE-0730256 OCE-0349177) and USAID (cooperative agreement 497-A-00-10-00008-00) for funding the international research collaborations highlighted in this manuscript. We also thank the governments of Indonesia (RISTEK, LIPI, and PHKA) and Philippines (NFRDI) for permitting the collaborative research and education activities herein. This material is based upon work supported by the National Science Foundation through the National Evolutionary Synthesis Center (NESCent) under grant number NSF \#EF-0905606. A special thanks goes to C Riginos, and the National Evolutionary Synthesis Center for organizing and hosting the Molecular Ecology and Evolution of the Indo-Pacific Catalysis meeting that lead to this paper.

\section{Author Contributions}

This paper is the result of a NESCent working group on the molecular ecology and evolution of the Indo-Pacific. Most authors contributed to the conceptualization and outlining of this paper at this catalysis meeting and all contributed to the writing. Specifically, PH Barber led the writing and overall organization. MCA Ablan-Lagman, R Ravago-Gotanco, and MA Juinio- Meñez led the writing of challenges and progress in the Philippines. Ambariyanto, D Cahyani, IGN Mahardika, AHA Toha, and AW Anggoro led the writing of challenges and progress in Indonesia. K Shanker and RGS Berlinck wrote on issues in India and Brazil, respectively. ED Crandall, CJ Starger, and DA Willette led the writing about the NSF PIRE project.

\section{DisClAimer}

The views expressed in this paper those of the authors and do not represent any official policy of the United States Department of State.

\section{Literature Cited}

Adams WM, Aveling R, Brockington D, Dickson B, Elliott J, Hutton J, Roe D, Vira B, Wolmer W. 2004. Biodiversity conservation and the eradication of poverty. Science. 306(5699):11461149. PMid:15539593. http://dx.doi.org/10.1126/science.1097920

Ahmed MM, Chung KY, Wichenseher JW. 2003. Business students' perception of ethics and moral judgment: a cross-cultural study. J Bus Ethics. 43:89-102. http://dx.doi. org/10.1023/A:1022915316112

Alho CJR. 2008. The value of biodiversity. Br J Biol. 68(4):1115-1118. http://dx.doi.org/10.1590/ S1519-69842008000500018

Barnosky AD, Matzke N, Tomiya S, Wogan GOU, Swartz B, Quental TB, Marshall C, McGuire JL, Lindsey EL, Maguire KC, et al. 2011. Has the Earth's sixth mass extinction already arrived? Nature. 471(7336):51-57. PMid:21368823. http://dx.doi.org/10.1038/nature09678

BarrettCB, BrandonK, Gibson C, Gjertsen H.2001.Conservingtropicalbiodiversityamidweakinstitutions. Bioscience.51:497-502.http://dx.doi.org/10.1641/0006-3568(2001)051[0497:CT BAWI]2.0.CO;2

Bellwood DR, Meyer CP. 2009. Searching for heat in a marine biodiversity hotspot. J Biogeogr. 36(4):569-576. http://dx.doi.org/10.1111/j.1365-2699.2008.02029.x

Bhaskaran A, Rajan PD. 2010. Advancing the science of taxonomy in India. Curr Sci. 99(2):157-158. 
Blum E. 1993. Making biodiversity profitable: a case study of the Merck/INBio agreement. Environment. 35(4):16-45. http://dx.doi.org/10.1080/00139157.1993.9929092

Brito Cruz CH, Chaimovich H. 2010. Brazil, in UNESCO Science Report 2010: The Current Status of Science around the World - Executive Summary.

Burke L, Reytar K, Spalding M, Perry A. 2011. Reefs at risk revisited. Washington DC: World Resources Institute.

Butchart SHM, Walpole M, Collen B, van Strien A, Scharlemann JPW, Almond REA, Baillie JEM, Bomhard B, Brown C, Bruno J, et al. 2010. Global biodiversity: indicators of recent declines. Science. 328(5982):1164-1168. PMid:20430971. http://dx.doi.org/10.1126/ science. 1187512

Cardinale BJ, Duffy JE, Gonzalez A, Hooper DU, Perrings C, Venail P, Narwani A, Mace GM, Tilman D, Wardle DA, et al. 2012. Biodiversity loss and its impact on humanity. Nature. 486(7401):59-67. PMid:22678280. http://dx.doi.org/10.1038/nature11148

Casilagan ILN, Juinio-Meñez MA, Crandail ED. Genetic diversity, population structure, and demographic history of exploited sea urchin populations (Tripneustes gratilla) in the Philippines. J Exp Mar Biol Ecol. 449:284-293. http://dx.doi.org/10.1016/j. jembe.2013.09.012

Chivian E, Bernstein A. 2008. Sustaining life-how human health depends on biodiversity. Oxford University Press. PMid:18845759.

Clapham P. 2005. Publish or perish. Bioscience. 55:390-391. http://dx.doi. org/10.1641/0006-3568(2005)055[0390:POP]2.0.CO;2

Cragg GM, Katz F, Newman DJ, Rosenthal J. 2012. The impact of the United Nations Convention on Biological Diversity on natural products research. Nat Product Reports. 29(12):14071423. PMid:23037777. http://dx.doi.org/10.1039/c2np20091k

Dalton R. 2004. Bioprospectors hunt for fair share of profits. Nature. 427(6975):576-576. PMid:14961086. http://dx.doi.org/10.1038/427576a

Danielsen F, Mendoza MM, Alviola P, Balete DS, Enghoff M, Poulsen MK, Jensen AE. 2003. Biodiversity monitoring in developing countries: what are we trying to achieve? Oryx. 37:407-409. http://dx.doi.org/10.1017/S0030605303000735

Davis MS. 2003. The role of culture in research misconduct. Accountability Res. 10:189-201. PMid:14979320. http://dx.doi.org/10.1080/714906092

DeBoer TS, Naguit MR, Erdmann MV, Ablan-Lagman MCA, Ambariyanto, Carpenter KE, Toha AHA, Barber PH. 2014. Concordance between phylogeographic and biogeographic boundaries in the Coral Triangle: conservation implications based on comparative analyses of multiple giant clam species. Bull Mar Sci. 90:277-299. http://dx.doi.org/10.5343/ bms.2013.1003

De Rond M, Miller AN. 2005. Publish or perish-bane or boon of academic life? J Manage Inquiry. 14:321-329. http://dx.doi.org/10.1177/1056492605276850

Dean W. 1995 With broadax and firebrand: the destruction of the Brazilian Atlantic forest. Berkeley: University of California Press. p. 504.

Diaz S, Fargione J, Chapin FS III, Tilman D. 2006. Biodiversity loss threatens human wellbeing. Plos Biology. 4(8):1300-1305. PMid:16895442. PMCid:PMC1543691. http://dx.doi. org/10.1371/journal.pbio.0040277

Dolan AH, Taylor M, Neis B, Ommer R, Eyles J, Schneider D, Montevecchi B. 2005. Restructuring and health in Canadian coastal communities. EcoHealth. 2:195-208. http:// dx.doi.org/10.1007/s10393-005-6333-7

Drew JA. 2005. Use of traditional ecological knowledge in marine conservation. Conserv Biol. 19:1286-1293. http://dx.dol.org/10.111//.1523-1739.2005.00158.x

Drew JA, Buxman CL, Holmes DD, Mandecki JL, Mungkaje AJ, Richardson AC, Westnead MW. 2012. Biodiversity inventories and conservation of the marine fishes of Bootless Bay, Papua New Guinea. BMC Ecol. 12:15. PMid:22849436. PMCid:PMC3515464. http://dx.doi. org/10.1186/1472-6785-12-15 
Easterbrook G. 1994. The spotted owl-an environmental parable-the birds. New Republic. 210(13):22-27.

Ehrlich PR, Pringle RM. 2008. Where does biodiversity go from here? A grim business-as-usual forecast and a hopeful portfolio of partial solutions. Proc Natl Acad Sci USA. 105:11,579_ 11,586. PMid:18695214. PMCid:PMC2556413. http://dx.doi.org/10.1073/pnas.0801911105

Fearnside PM. 1999. Biodiversity as an environmental service in Brazil's Amazonian forests: risks, value and conservation. Environ Conserv. 26(4):305-321. http://dx.doi.org/10.1017/ S0376892999000429

Ferreira de Souza PHG. 2012. Poverty, inequality and social policies in Brazil, 1995-2009. Brasilia: International Policy Centre for Inclusive Growth (IPC-IG). p. 28.

Fisher R, Radford BT, Knowlton N, Brainard RE, Michaelis FB, Caley MJ. 2011. Global mismatch between research effort and conservation needs of tropical coral reefs. Conserv Lett. 4(1):64-72. http://dx.doi.org/10.1111/j.1755-263X.2010.00146.x

Freudenburg WR, Wilson Lj, O'Leary DJ. 1998. Forty years of spotted owls? A longitudinal analysis of logging industry job losses. Sociological Perspect. 41(1):1-26. http://dx.doi. org $/ 10.2307 / 1389351$

Fuentes M. 2011. Economic growth and biodiversity. Biodiversity Conserv. 20(14):3453-3458. http://dx.doi.org/10.1007/s10531-011-0132-y

Gallai N, Salles JM, Settele J, Vaissiere BE. 2009. Economic valuation of the vulnerability of world agriculture confronted with pollinator decline. Ecol Econ. 68(3):810-821. http:// dx.doi.org/10.1016/j.ecolecon.2008.06.014

Greenland P, Fontanarosa PB. 2012. Ending honorary authorship. Science. 337(6098):10191019. PMid:22936744. http://dx.doi.org/10.1126/science.1224988

Hooper DU, Chapin FS, Ewei I), Hector A, Inchausti P, Lavorel S, Lawton JH, Lodge DM, Loreau M, Naeem S, et al. 2005. Effects of biodiversity on ecosystem functioning: a consensus of current knowledge. Ecol Monogr. 75(1):3-35. http://dx.doi.org/10.1890/04-0922

Jenkins M. 2003. Prospects for biodiversity. Science. 302(5648):1175-1177. PMid:14615529. http://dx.doi.org/10.1126/science.1088666

Joly CA, Rodrigues RR, Metzger JP, Haddad CFB, Verdade LM, Oliveira MC, Bolzani VS. 2010. Biodiversity conservation research, training, and policy in Sao Paulo. Science. 328(5984):1358-1359. PMid:20538935. http://dx.doi.org/10.1126/science.1188639

Keppel G, Morrison C, Watling D, Tuiwawa M, Rounds 1A. 2012. Conservation in tropical Pacific Island countries: why most current approaches are failing. Conserv Lett. 5:256-265. http://dx.doi.org/10.1111/j.1755-263X.2012.00243.x

Langlois EV, Campbell K, Prieur-Richard AH, Karesh WB, Daszak P. 2012. Towards a better integration of global health and biodiversity in the new sustainable development goals beyond Rio+20. EcoHealth. http://dx.doi.org/10.1007/s10393-012-0800-8

Leta J, Chaimovich H. 2002. Recognition and international collaboration: the Brazilian case. Scientometrics. 53(3):325-335. http://dx.doi.org/10.1023/A:1014868928349

Levin PS, Levin DA. 2002. The real biodiversty crisis. Am Sci. 90(1):6-8.

Lovejoy TE. 1994. The quantification of biodiversity: an esoteric quest or a vital component of sustainable development? R Soc Philos Trans Biol Sci. 345(1311):81-87. PMid:7972359. http://dx.doi.org/10.1098/rstb.1994.0089

Mace GM, Cramer W, Diaz S, Faith DP, Larigauderie A, Le Prestre P, Palmer M, Perrings C, Scholes RJ, Walpole M, et al. 2010. Biodiversity targets after 2010. Curr Opin Environ Sustainability. 2(1-2):3-8. http://dx.doi.org/10.1016/j.cosust.2010.03.003

Madhusudan MD, Shanker K, Kumar A, Mishra C, Sinha A, Arthur R, Datta A, Rangarajan M, Chellam R, Shahabuddin G, et al. 2006. Science in the wilderness: the predicament of scientific research in India's wildlife reserves. Curr Sci. 91:1015-1019.

Mansfield E. 1995. Academic research underlying industrial innovations: sources, characteristics, and financing. Rev Econ Statistics. 77(1):55-65. http://dx.doi.org/10.2307/2109992

May RM. 1997. The scientific wealth of nations. Science. 275:/93-796. http://dx.doi. org $/ 10.1126 /$ science.275.5301.793 
McMichael AJ, Friel S, Nyong A, Corvalan C. 2008. Global environmental change and health: impacts, inequalities, and the health sector. BMJ. 336(7637):191-194. PMid:18219041. PMCid:PMC2214484. http://dx.doi.org/10.1136/bmj.39392.473727.AD

Meyer SM. 1995. The economic impact of environmentai regulation. J Environ Law Practice. 3(2):4-15.

Meyer SM. 1997. The economic impact of the Endangered Species Act on the housing and real estate markets. NYU Environ Law J. 6(2):450-478.

Mikkelsen PM, Cracraft J. 2001. Marine biodiversity and the need for systematic inventories. Bull Mar Sci. 69(2):535-534.

Myers N, Mittermeier RA, Mittermeier CG, da Fonseca GAB, Kent J. 2000. Biodiversity hotspots for conservation priorities. Nature. 403(6772):853-858. PMid:10706275. http:// dx.doi.org/10.1038/35002501

Newman DJ, Cragg GM. 2007. Natural products as sources of new drugs over the last 25 years. J Nat Products. 70(3):461-477. PMid:17309302. http://dx.doi.org/10.1021/np068054v

Newman DJ, Cragg GM. 2010. Natural products as drugs and leads to drugs: the historical perspective. In: Buss AD, Butler MS, editors. Natural product chemistry for drug discovery. The Royal Society of Chemistry. p. 440.

Normile D. 2010. Saving forests to save biodiversity. Science. 329(5997):1278-1280. PMid:20829464. http://dx.doi.org/10.1126/science.329.5997.1278

NRC. 2005. Valuing ecosystem services: toward better environmental decision-making. The National Academies Press.

Pennisi E. 1998. Genetic ownership-Brazil wants cut of its biological bounty. Science. 279(5356):1445-1445. PMid:9508717. http://dx.doi.org/10.1126/science.279.5356.1445a

Pennisi E. 2013. Costa Rica's INBio facing government ballout. http://news.sciencemag.org/ environment/2013/04/costa-ricas-inbio-facing-government-bailout.

Pergams ORW, Zaradic PA. 2006. Is love of nature in the US becoming love of electronic media? 16-year downtrend in national park visits explained by watching movies, playing video games, internet use, and oil prices. J Environ Manage. 80(4):387-393. PMid:16580127. http://dx.doi.org/10.1016/j.jenvman.2006.02.001

Pergams ORW, Zaradic PA. 2008. Evidence for a fundamental and pervasive shift away from nature-based recreation. Proc Natl Acad Sci USA. 105(7):2295-2300. PMid:18250312. PMCid:PMC2268130. http://dx.doi.org/10.1073/pnas.0709893105

Pethiyagoda R. 2004. Biodiversity law has had some unintended effects. Nature. 429:129. PMid:15141185. http://dx.doi.org/10.1038/429129a

Pimenta BVS, Haddad CFB, Nascimento LB, Cruz CAG, Pombal JP. 2005. Comment on "Status and trends of amphibian declines and extinctions worldwide." Science. 309(5743). PMid:16179460. http://dx.doi.org/10.1126/science.1112996

Pimm SL, Russell GJ, Gittleman 1L, Brooks TM. 1995. The future of biodiversity. Science 269(5222):347-350. PMid:17841251. http://dx.doi.org/10.1126/science.269.5222.347

Prathapan KD, Rajan PD. 2009. Protectionism and natural history research in India. Curr Sci. 97(10):1411-1413.

Prathapan KD, Rajan PD. 2011. Biodiversity access and benefit-sharing: weaving a rope of sand. Curr Sci. 100(3):290-293.

Rajan PD, Prathapan KD. 2009. Shared ownership of biological resources. Science. 324:10141015. PMid:19460983. http://dx.doi.org/10.1126/science.324_1014c

Rands MRW, Adams WM, Bennun L, Butchart SHM, Clements A, Coomes D, Entwistle A, Hodge I, Kapos V, Scharlemann JPW, et al. 2010. Biodiversity conservation: challenges beyond 2010. Science. 329(5997):1298-1303. PMid:20829476. http://dx.doi.org/10.1126/ science.1189138

Raynal JM, Crandall ED, Barber PH, Mahardika GN, Lagman MC, Carpenter KE. 2014. Basin isolation and oceanographic features influencing lineage divergence in the humbug damselfish (Dascyllus aruanus) in the Coral Triangle. Bull Mar Sci. 90:513-532. http://dx.doi. org/10.5343/bms.2013.1017 
Ready T. 2002. "Biopiracy" issue stops research. Nat Med. 8(1):9-9. PMid:11786889. http:// dx.doi.org/10.1038/nm0102-9b

Reaka ML. 1997. The global biodiversity of coral reefs: a comparison with rain forests. In: Reaka-Kudla ML, Wilson DE, Wilson EO, editors. Biodiversity II: understanding and protecting our biological resources. Washington, DC: Joseph Henry Press. p. 83-108.

Regalado A. 2010. Brazillian science: riding a gusher. Science. 330:1306-1312. PMid:21127226. http://dx.doi.org/10.1126/science.330.6009.1306

Ribeiro MC, Metzger JP, Martensen AC, Ponzonı FT, Hirota MM. 2009. The Brazilian Atlantic Forest: how much is left, and how is the remaining forest distributed? Implications for conservation. Biol Conserv. 142(6):1141-1153. http://dx.doi.org/10.1016/j.biocon.2009.02.021

Roberts CM, McClean CJ, Veron JEN, Hawkins JP, Allen GR, McAllister DE, Mittermeier CG, Schueler FW, Spalding M, Wells F, et al. 2002. Marine biodiversity hotspots and conservation priorities for tropical reefs. Science. 295(5558):1280-1284. PMid:11847338. http:// dx.doi.org/10.1126/science.1067728

Rodrigues ASL, Gray CL, Crowter BJ, Ewers RM, Stuart SN, Whitten T, Manica A. 2010. A global assessment of amphibian taxonomic effort and expertise. Bioscience. 60(10):798806. http://dx.doi.org/10.1525/bio.2010.60.10.6

Rodrigues RR, Lima RAF, Gandolifi S, Nave AG. 2009. On the restoration of high diversity forests: 30 years of experience in the Brazilian Atlantic Forest. Biol Conserv. 142(6):12421251. http://dx.doi.org/10.1016/j.biocon.2008.12.008

Service RF. 2012. Satellite labs extend science. Science. 337(6102):1600-1603. PMid:23019625. http://dx.doi.org/10.1126/science.337.6102.1600

Shackleton CM. 2001. Re-examining local and market-orientated use of wild species for the conservation of biodiversity. Environ Conserv. 28(3):270-278. http://dx.doi.org/10.1017/ S0376892901000285

Shyamsundar P, Lanier GK. 1994. Biodiversity prospecting: an effective conservation tool? Trop Biodivers. 2(3):441-446.

Sodhi NS, Koh LP, Brook BW, Ng PKL. 2004. Southeast Asian biodiversity: an impending disaster. Trends Ecol Evol. 19(12):654-660. PMid:16701328. http://dx.doi.org/10.1016/j. tree.2004.09.006

Sodhi NS, Liow LH. 2000. Improving conservation biology research in Southeast Asia. Conserv Biol. 14(4):1211-1212. http://dx.doi.org/10.1046/j.1523-1739.2000.99416.x

Stokstad E. 2010. Despite progress, biodiversity declines. Science. 329(5997):1272-1273. PMid:20829462. http://dx.doi.org/10.1126/science.329.5997.1272

Thomas CD, Cameron A, Green RE, Bakkenes M, Beaumont L), Collingham YC, Erasmus BFN, de Siqueira MF, Grainger A, Hannah L, et al. 2004. Extinction risk from climate change. Nature. 427(6970):145-148. PMid:14712274. http://dx.doi.org/10.1038/nature02121

Tisdell CA. 1999. Biodiversity, conservation and sustanable development: principles and practices with Asian examples. Cheltenham: Edward Elgar. PMid:10472675.

Toledo A, Burlingame B. 2006. Biodiversity and nutrition: a common path toward global food security and sustainable development. J Food Composition Analysis. 19(6-7):477-483. http://dx.doi.org/10.1016/j.jfca.2006.05.001

Tollefson J. 2012. Brazil set to cut forest protection. Nature. 485(7396):19. PMid:22552069. http://dx.doi.org/10.1038/485019a

Turner WR, Brandon K, Brooks TM, Gascon C, Gibbs HK, Lawrence KS, Mittermeier RA, Selig ER. 2012. Global biodiversity conservation and the alleviation of poverty. Bioscience. 62(1):85-92. http://dx.doi.org/10.1525/bio.2012.62.1.13

UNESCO. 2013. United National Educational, Scientific, and Cultural Organization Institute for Statistics Data Center. Available from: http://stats.uis.unesco.org/unesco/TableViewer/ document.aspx?ReportId=136\&IF_Language=eng\&BR_Topic $=0$.

UNEP. 2011. Secretariat of the Convention on Biological Diversity United Nations Environment Programme. Available from: http://www.cbd.int/doc/press/2011/pr-2011-05-05-barometer-en.pdf. 
Wake DB, Vredenburg VT. 2008. Are we in the midst of the sixth mass extinction? A view from the world of amphibians. Proc Natl Acad Sci USA. 105:11,466-11,473. PMid:18695221. PMCid:PMC2556420. http://dx.doi.org/10.1073/pnas.0801921105

Willette DA, Carpenter KE, Santos MD. 2014a. Evolution of the freshwater sardinella, Sardinella tawilis (Clupeiformes: Clupeidae), in Taal Lake, Philippines and identification of its marine sister-species, Sardinella hualiensis. Bull Mar Sci. 90:455-470. http://dx.doi. org/10.5343/bms.2013.1010

Willette DA, SeebJE, Allendorf FW,Barber PH, Barshis DJ, Carpenter KE, CrandallED, Cresko WA, Fernandez-SilvaI, Matz MV, Meyer E, Seeb LW. 2014b. So, you want to use nextgeneration sequencing in marine systems? Insight from the Pan-Pacific Advanced Studies Institute. Bull Mar Sci. 90:79-122. http://dx.doi.org/10.5343/bms.2013.1008

Willis KJ, Birks H)B. 2006. What is natural? The need for a long-term perspective in biodiversity conservation. Science. 314(5803):1261-1265. PMid:17124315. http://dx.doi.org/10.1126/ science. 1122667

Wislar JS, Flanagin A, Fontanarosa PB, DeAngelis CD. 2011. Honorary and ghost authorship in high impact biomedical journals: a cross sectional survey. BMJ. 343.

World Bank. 2013a. World Development Indicators Database. Available from: http://databank.worldbank.org/data/views/variableSelection/selectvariables. aspx? source $=$ world-development-indicators.

World Bank. 2013b. Patent applications, residents. Available from: http://data.worldbank.org/ indicator/IP.PAT.RESD

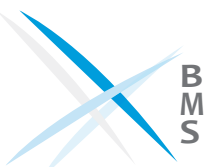

